\title{
LEITURA LITERÁRIA DA BÍBLIA: UM PROJETO
}

João Leonel ${ }^{\star}$

(iD) https://orcid.org/0000-0003-3600-3695

Anderson de Oliveira Lima**

D https://orcid.org/0000-0002-0039-1000

Cristhiano Motta Aguiar ${ }^{* *}$

(iD) https://orcid.org/0000-0003-4334-691X

Jonathan Luis Hack ${ }^{* * *}$

https://orcid.org/0000-0003-0124-6822

Como citar este artigo: LEONEL, J.; LIMA, A. de O.; AGUIAR, C. M.; HACK, J. L. Leitura literária da Bíblia: um projeto. Todas as Letras - Revista de Lingua e Literatura, São Paulo, v. 22, n. 3, p. 1-16, set./dez. 2020. DOI 10.5935/1980-6914/eLETLT 2012480

Submissão: maio de 2019. Aceite: setembro de 2019.

Resumo: Este artigo apresenta o projeto de pesquisa "Análise literária de narrativas: novas metodologias para o ensino da interpretação bíblica", bem como seus resultados. O projeto foi desenvolvido durante o ano de 2018 com financiamento do Fundo MackPesquisa, trabalhando com a aplicação de princípios teórico-literários na interpretação de textos narrativos presentes na Bíblia. Como um dos resultados do projeto, será lançado em 2021 um livro com capítulos escritos pelos membros do grupo e convidados oriundos de universidades nacionais e internacionais.

Palavras-chave: Literatura. Narrativa. Bíblia. Interpretação. Leitura.

\footnotetext{
* Universidade Presbiteriana Mackenzie (UPM), São Paulo, SP, Brasil. E-mail: joao.leonel@uol.com.br

** Universidade de São Paulo (USP), São Paulo, SP, Brasil. E-mail: anderson.angela.lima@gmail.com

*** Universidade Presbiteriana Mackenzie (UPM), São Paulo, SP, Brasil. E-mail: cristhianoaguiar@gmail.com
}

**** Universidade Presbiteriana Mackenzie (UPM), São Paulo, SP, Brasil. E-mail: jonathan_hack@yahoo.com.br 


\section{INTRODUÇÃO}

$\mathbf{A}$

o longo do ano de 2018, pesquisadores, professores e alunos vinculados ao grupo de pesquisa Numep (Núcleo Multidisciplinar de Estudos do Protestantismo), CNPq e aos cursos de graduação em Teologia e graduação e pós-graduação em Letras da Universidade Presbiteriana Mackenzie (UPM) desenvolveram o projeto de pesquisa que recebeu o título de "Análise literária de narrativas: novas metodologias para o ensino da interpretação bíblica", financiado pelo Fundo Mackenzie de Pesquisa (MackPesquisa).

O projeto surgiu com o objetivo de aprofundar os conhecimentos do grupo e de beneficiar, de maneira imediata, estudantes que ingressam nos cursos de graduação e pós-graduação da UPM, principalmente nas áreas de Letras e Teologia, e de outras instituições. Para isso, foram organizados eventos, publicados textos acadêmicos, desenvolvido site com conteúdo diverso, direcionados recursos para aquisição de obras da área para as bibliotecas da instituição e foi iniciada a organização de um livro.

O grupo de pesquisa atuou por 12 meses com a finalidade de produzir material visando, por um lado, aproximar os pesquisadores e leitores brasileiros dos estudos bíblicos aos conteúdos e aplicações da Teoria Literária e aos textos sagrados e, de outro, trazer estudantes e pesquisadores do campo literário para o conhecimento e estudo de textos bíblicos.

Concluído o projeto, o grupo continua ativo, abordando articulações entre teorias e textos religiosos com vistas a identificar, problematizar e aprofundar as relações entre a Bíblia e teorias literárias, e entre a literatura, principalmente brasileira, e temáticas bíblico-religiosas nela presentes. A existência e a produção do grupo reafirmam a posição pioneira assumida pela UPM no contexto de estudos sobre Bíblia como literatura, um campo bem conhecido nos Estados Unidos e na Europa que vai, ainda que timidamente, inserindo-se no cenário acadêmico brasileiro.

Este artigo visa problematizar o tema, demonstrar a relevância do projeto, apresentar os objetivos que nos conduziram a tal empreendimento, divulgar parcialmente os resultados e incentivar novas pesquisas na área.

\section{Desenvolvimento}

Partindo do interesse do leitor brasileiro pela Bíblia' ${ }^{1}$, procuramos inicialmente conhecer os trabalhos que, especialmente a partir das décadas de 1970 e 1980, passaram a aplicar as teorias literárias e metodologias criticas mais recentes aos estudos bíblicos, produzindo uma significativa mudança de paradigmas na história da leitura bíblica.

Em contexto europeu, norte-americano e canadense, críticos e teóricos literários de destaque começaram, nesse período, a analisar os textos bíblicos sob novo enfoque, alcançando resultados tão surpreendentes quanto promissores. Isso pode ser notado, por exemplo, nas obras de Robert Alter (1981), Northrop Frye (1982), John B. Gabel e Charles B. Wheeler (1986) e Alter e Frank Kermode (1987). E, mais tardiamente, com Harold Bloom (2012).

\footnotetext{
A Bíblia ocupa o primeiro lugar como livro mais lido no Brasil nas quatro edições da pesquisa Retratos da Leitura no Brasil, publicadas nos anos de 2001, 2007, 2011, 2015 e 2019. Disponível em: https://prolivro.org.br/pesquisas-retratos-da-leitura/ as-pesquisas-2/.
} 
Seguindo seus passos e em diálogo com eles, um segundo grupo de autores, composto essencialmente por biblistas e teólogos que também se interessaram pelos recursos da Teoria Literária para a interpretação dos textos bíblicos, passou a desenvolver seus trabalhos. É o caso de Adele Berlin (1983), Leland Ryken (1984, 1992), Meir Sternberg (1987), Tremper Longman III (1987), Shimon Bar-Efrat (1989), Mark A. Powell (1990), Jan P. Fokkelman (1995)² e Daniel Marguerat e Yvan Bourquin (1998) ${ }^{3}$, entre outros.

Nas últimas décadas tem se tornado mais comum lermos sobre a Bíblia como literatura; esse tem sido, inclusive, o nome de um considerável número de livros publicados em língua inglesa, como lembra Anderson de Oliveira Lima (2015, v. 9 , n. 1, p. 154, nota n. 1):

No cenário norte-americano e europeu, o leitor pode encontrar uma variedade considerável de obras disponíveis com títulos desse tipo ao fazer uma pesquisa superficial pela expressão "The Bible as Literature" nalgum site que comercializa livros. Por exemplo, encontramos: de Glen Cavaliero e T. R. Henn, a Taunton Press publicou The Bible as Literature em 2008. A Lightning Source publicou em 2006 outro The Bible as Literature, dessa vez de Irving Francis Wood e Elihu Grant. Também temos um The Bible as Literature, de John P. Peters, Richard Green Moulton e A. B. Bruce, publicado pela Bibliolife em 2009. Além disso, há muitos outros títulos parecidos, como a obra de James S. Acker Man e Thayer S. Warshaw intitulada The Bible as/in Literature de 1995 pela Prentice Hall, $e$ Reading the Bible as Literature: An Introduction, de Jeanie C. Crain, publicado em 2010 pela Polity Press.

O mercado editorial brasileiro começou a se dedicar à tradução de autores estrangeiros que pesquisam a área tardiamente. Houve um início tímido a partir da década de 1990 e um desenvolvimento mais consistente nos anos 2000 e seguintes. Por exemplo, o livro The art of biblical narrative, do crítico norte-americano Robert Alter, que costuma ser apontado como o marco inicial da produção dos estudos literários da Bíblia, foi publicado originalmente em 1981, vindo a ganhar edição brasileira somente em 2007, como A arte da narrativa bíblica. $\mathrm{O}$ mesmo pode ser dito de The great code: the Bible and literature, importante texto teórico da área de autoria do crítico literário canadense Northrop Frye: a obra é de 1982 e só chegou ao leitor brasileiro em 2004 com o título O código dos códigos: a Biblia e a literatura. Período mais longo ainda levou o How to read the Bible as literature... and get more out of it, de Leland Ryken, para chegar até nós. Trinta e três anos! O original de 1984 recebeu título em português de Para ler a Bíblia como literatura: e aprender ainda mais com ela em 2018. O texto de John B. Gabel e Charles B. Wheeler, The Bible as literature: an introduction, não demorou tanto quanto os demais. O original é de 1986 e sua publicação ocorreu em 1993. The literary guide to the Bible, de Alter e Kermode, de 1987, veio à luz em nosso idioma dez anos depois como Guia literário da Bíblia. Por fim, o livro Pour lire les récits bibliques. La Bible se raconte. Initiation à l'analyse narrative surgiu no cenário francês em 1998, chegando ao nosso mercado editorial apenas em 2009 como Para ler as narrativas bíblicas: iniciação à análise narrativa.

\footnotetext{
2 Texto publicado em 1995 originalmente em holandês com o título Vertelkunst in de bijbel een handleiding bij literair lezen, e posteriormente traduzido e publicado em inglês em 1999 como Reading biblical narrative: an introductory guide.

3 Tradução publicada no Brasil em 2009.
} 
Apesar das dificuldades apontadas, algumas editoras brasileiras começam a publicar textos de autores nacionais. Podemos citar Leia a Bíblia como literatura, de Cássio Murilo Dias da Silva, lançado pela Loyola em 2007. Nesse mesmo ano a Hagnos publicou o Manual de Exegese, de Júlio Paulo Tavares Zabatiero, que propõe o estudo exegético da Bíblia mediado por teorias semióticas. A Paulus, por sua vez, trouxe à luz Bíblia, literatura e linguagem, do mesmo Júlio Zabatiero em parceria com João Leonel em 2011. E as Paulinas, pela série "Bíblia como Literatura", publicou dois textos. De Zuleica Silvano, Introdução à análise poética de textos bíblicos, em 2014, e de Jaldemir Vitório, Análise narrativa da Bíblia: primeiros passos de um método, em 2016.

Não deixa de ser importante mencionar que pesquisadores do grupo também contribuíram para o desenvolvimento dos estudos da Bíblia como literatura no contexto da pós-graduação em Letras da UPM. Três dissertações de mestrado devem ser mencionadas. Leni Fernandes escreveu sobre Imagens da mulher no evangelho de Mateus: a construção de personagens femininas, em 2014. Francikley Vito produziu a dissertação Logos em luta: diálogo como artifício literário no Quarto Evangelho, também em 2014, e Ricardo César Toniolo defendeu dissertação em 2017 com o título O narrador no livro das crônicas: estratégias narrativas para o estabelecimento de um novo discurso religioso.

Três teses doutorais também foram defendidas nos últimos anos nesse mesmo programa de pós-graduação. A primeira, em 2015, por Anderson de Oliveira Lima, intitulada A Bíblia como literatura no Brasil: história e análise de novas práticas de leitura bíblica. A segunda, Gênesis 38: análise literária e história da leitura, de Jonathan Luís Hack, em 2017. E a última, no começo deste ano, desenvolvida por Leni Soares Vieira Fernandes, recebeu o título "Os céus e a terra passarão, mas as minhas palavras não hão de passar": os efeitos dos cronotopos no evangelho de Mateus ${ }^{4}$.

O começo do interesse pelos estudos da Bíblia como literatura em contexto brasileiro vai ao encontro do que Frederico Lourenço, linguista português, professor de literatura clássica em Coimbra e que está atualmente envolvido com um projeto de tradução da Bíblia do grego para o português (2017, 2018, 2019), escreveu sobre a recente atenção que círculos acadêmicos têm dispensado ao estudo literário da Bíblia:

Trata-se de uma tendência crescente em nivel internacional: nas grandes universidades do mundo (Harvard, Yale, Princeton, Oxford, Cambridge etc.), a Bíblia está cada vez mais presente, nos cursos de graduação e pós-graduação em humanidades, como matéria de estudo universitário entendido sob uma forma não religiosa (BÍBLIA, 2017, p. 18).

A análise literária de narrativas, em conformidade com os moldes propostos pelos teóricos literários citados anteriormente, prioriza em seus primórdios a identificação dos mecanismos de produção de sentido utilizados nos textos para impactar os leitores. A aplicação das teorias no campo dos estudos bíblicos exigiu algumas redefinições relativas ao próprio texto da Bíblia. Nesse sentido, em 1978, com o olhar voltado para o Novo Testamento, o exegeta Norman R. Petersen escreve Literary criticism for New Testament critics. Inicialmente, ele busca uma

4 As dissertações e teses foram orientadas pelo prof. dr. João Leonel. 
redefinição de "texto" e, na sequência, propõe os caminhos para a interpretação. Seu objetivo é "[...] saber como os críticos literários concebem os textos" (PETERSEN, 1978, p. 23, tradução nossa). Para tanto, parte de uma análise crítica das metodologias utilizadas na exegese bíblica, uma vez que abordam os textos neotestamentários em perspectiva evolutiva, visando principalmente à reconstrução histórica, social e religiosa dos grupos cristãos do primeiro século depois de Cristo. Para ele, os exegetas seguiam escolas teórico-literárias ultrapassadas. Segundo sua avaliação,

Críticos do século 19 e início do 20 conceberam textos como se fossem janelas pelas quais se chegaria ao significado que estava para além deles. Mas contra tal posição o Novo Criticismo anglo-americano e movimentos similares em outros países nas primeiras décadas deste século [século 20] se rebelaram ao propor os textos como espelhos nos quais o sentido estava presente (PETERSEN, 1978, p. 24, tradução nossa).

Utilizando a metáfora da "janela" e do "espelho", Petersen (1978, p. 25, tradução nossa) define seu percurso: "[...] comecemos nossa busca por um modelo crítico-literário refletindo sobre a mudança de ênfase da crítica literária, da janela para o espelho".

A conclusão a que chega Petersen é que os textos bíblicos devem ser estudados em si mesmos, em um exercício de close reading, ou seja, de uma leitura cujo foco seja colocado nas particularidades da construção textual e de seu sentido, desvinculada de fatores externos ao texto. Como aplicação do método, ele analisa os evangelhos de Marcos e Lucas, assim com o livro de Atos, a partir de seus enredos e de construções de mundos textuais (PETERSEN, 1978, p. 49-92).

Em 1979, Shimon Bar-Efrat (1989, p. 7, tradução nossa), seguindo basicamente na mesma direção que Petersen, indica o objetivo pelo qual escreve Narrative art in the Bible: "O propósito deste livro é fornecer um guia para a compreensão da narrativa bíblica como uma obra de arte literária”. A justificativa se aproxima daquela apresentada pelo autor citado anteriormente, embora, em lugar da crítica aos métodos de exegese tradicionais, Bar-Efrat (1989, p. 9, tradução nossa) lamente naquele momento a ausência de estudos literários sobre a Bíblia:

Mais de um terço da Bíblia Hebraica consiste em narrativas. Geralmente se reconhece que as narrativas bíblicas possuem a mais alta qualidade artística, estando entre os tesouros literários mais importantes do mundo. Na pesquisa acadêmica da Bíblia, no entanto, o estudo literário de narrativas bíblicas tem recebido apenas uma preocupação marginal.

Segundo o autor, "O objetivo da obra é propor uma leitura que se baseie no emprego de ferramentas e princípios utilizados no estudo da literatura [...]" (BAR-EFRAT, 1989, p. 7, tradução nossa). Para tanto, estuda elementos básicos para a análise de narrativas a partir dos seguintes capítulos: capítulo 1 . O narrador; capítulo 2. Os personagens; capítulo 3. O enredo; capítulo 4. Tempo e espaço; Capítulo 5. Estilo; Capítulo 6. A narrativa de Amom e Tamar, no qual estuda uma narrativa bíblica aplicando os princípios apresentados nos capitulos anteriores.

Robert Alter, em The art of biblical narrative, de 1981, avança ao especificar o tipo de análise que pratica. Ele chama a atenção para a necessidade de reco- 
nhecer convenções presentes nesses textos. Uma delas é a cena-padrão. Segundo o autor, "[...] há uma série de episódios recorrentes na vida dos heróis bíblicos que são análogos às cenas-padrão dos poemas homéricos, na medida em que dependem da manipulação de uma constelação fixa de motivos predeterminados" (ALTER, 2007, p. 85) ${ }^{5}$. Outra característica da literatura bíblica, principalmente do Antigo Testamento, é a “técnica de repetição". Para Alter (2007, p. 147),

A narrativa bíblica nos mostra, assim, um sistema cuidadosamente integrado de repetições, algumas baseadas na recorrência de fonemas, palavras ou pequenas frases, outras ligadas a ações, imagens e idéias que fazem parte do universo dos relatos que "reconstruímos" como leitores [...].

Já em 1998, no livro Pour lire les récits bibliques, Marguerat e Bourquin oferecem outro exemplo de mecanismo literário que atua na produção do sentido textual. Para eles, é importante identificar o "enquadramento", entendido como o contexto no qual se dá a ação dos personagens, composto de tempo, lugar e meio social com o qual se constrói uma narrativa:

Às vezes o enquadramento apresenta, de modo neutro, um meio em que evoluem os personagens; faz o papel dos advérbios na estrutura da frase, assinalando quando, onde e como se desenvolve a ação: ela se passa de manhã ou à tarde, na cidade ou nos campos, com uma mulher ou um operário. Mas, ao lado e para além dessas indicações factuais, o enquadramento pode estar carregado de valor metafórico: a história se desenvolve ao amanhecer (instante da promessa e da criação), ou numa sinagoga (lugar do encontro entre Deus e seu povo); pode implicar um fariseu, induzindo um confronto com a Lei. O enquadramento contribui, portanto, para a compreensão simbólica da ação (MARGUERAT; BOURQUIN, 2009, p. 97-98).

Embora exista variedade de enfoques e ênfase entre autores, principalmente nos primeiros proponentes do campo, é útil a sintese elaborada por Antonio Magalhães (2009, p. 127-129) ao propor pontos em comum nos trabalhos sobre a temática Bíblia como literatura.

1) A Bíblia é interpretada como obra literária, o que implica lê-la a partir das teorias literárias apropriadas, levando em conta tramas, personagens, estética, densidade narrativa, etc. [...] 2) A Bíblia é lida em sua pluralidade de narrativas, mas a partir de certa continuidade que existe nas "biografias" de seus personagens, algo importante para boa parte da literatura. Um dos pressupostos é que a Bíblia é rica e plural. [...] 3) A Bíblia é considerada obra basilar da literatura ocidental, emprestando-lhe temas, técnicas, personagens fortes, tramas sucintas mas cheias de suspense e criatividade [...] 4) Deus é personagem literário que, como qualquer outro personagem, cresce ou diminui à medida que dialoga com outros personagens. O importante aqui é explorar a densidade deste personagem em diálogo com outros.

Por razões metodológicas, para o desenvolvimento do projeto, optamos por trabalhar em três frentes: a primeira é a teórica, com o estudo de teorias literárias com vistas à definição e constituição de corpus teóricos adequados ao estudo

5 Esta citação e a próxima, assim como a de Marguerat e Bourquin, que vem em seguida, são retiradas da edição em português das referidas obras. 
da literatura bíblica. Conhecer obras que teorizam e demonstram como aplicar tais teorias à narrativa bíblica foi de suma importância para que ajustássemos nossos princípios de análise e também para que nos mantivéssemos cientes do atual estado da pesquisa.

Essa abordagem é majoritária nas obras sobre Bíblia e literatura mencionadas anteriormente, o que se justifica pelo fato de esse campo de estudos estar sendo estabelecido e necessitando, por decorrência, de maior investimento na definição e adaptação de teorias que sejam aplicáveis ao estudo de textos bíblicos. Há, aqui, a preponderância de estudos ligados à teoria literária e à teoria narrativa que buscam a definição do status do texto literário e sua aplicação ao texto bíblico, as características da construção narrativa e de seus elementos básicos: narrador, tempo, espaço, personagens, enredo. Em suma, busca-se enquadrar os textos bíblicos nos cânones dos textos ficcionais.

Cabe salientar que a escolha e a ênfase em teorias ligadas a textos narrativos por parte de exegetas provavelmente deriva de sua predileção por porções bíblicas escritas a partir desse gênero. Isso se justifica, em parte, pela presença de grandes blocos em prosa na Bíblia, como nos livros da Torá ${ }^{6}$, nos Profetas Anteriores $^{7}$, em alguns livros proféticos posteriores ${ }^{8}$ e em livros pertencentes ao último bloco do Antigo Testamento, os Escritos ${ }^{9}$. A preponderância da prosa se dá também nos livros do Novo Testamento. Os quatro evangelhos, assim como o livro de Atos e o Apocalipse foram escritos a partir desse gênero.

As pesquisas relacionadas a esse tópico, particularmente vinculadas a seus aspectos teóricos, embora não tenham sido majoritárias, produziram resultados bastante satisfatórios, que podem ser verificados a partir dos itens: a palestra proferida pelo dr. João Leonel, Bíblia como literatura: perspectivas e desenvolvimentos no Brasil e no exterior; o artigo do dr. Anderson de Oliveira Lima (2018, p. 57-65), "A teologia bíblica: convite a uma exegese laica"; e a comunicação proferida pela doutoranda Leni Soares Vieira, Um estudo sobre adaptações do texto bíblico de Josué 2.1-24: Raabe, a história de fé de uma prostituta.

Cabe mencionar que a ênfase sobre o estudo de narrativas tende a produzir, em contrapartida, o pouco interesse por outros gêneros igualmente presentes na Bíblia. O maior deles é o poético, que rege grande parte dos livros de sabedoria, bem como blocos consideráveis dos textos proféticos. Há também outros gêneros que ocupam espaço secundário no interesse dos estudiosos, como os legais, os visionários e os epistolográficos, por exemplo.

Tal constatação indica que as pesquisas em contexto brasileiro ligadas ao estudo da Bíblia como literatura deverão enfrentar o desafio de se voltar para os gêneros omitidos neste momento, a fim de que as abordagens de cunho "literário" da Bíblia possam, de fato, contemplar a diversidade de expressões textuais nela presentes.

Uma segunda frente trabalhada pelo grupo de pesquisa tratou da análise literária de textos bíblicos. Buscou-se, nesse contexto, aplicar as teorias ao estudo de textos específicos. Desejava-se exercitar a crítica literária nos textos da Bíblia.

\footnotetext{
6 Os primeiros cinco livros da Bíblia: Gênesis, Êxodo, Levítico, Números e Deuteronômio. Entre eles se encontram também outros gêneros, como o legal (partes de Êxodo, Levítico e Números) e o discursivo (praticamente todo o livro de Deuteronômio). Compostos pelos livros: Josué, Juízes, os dois livros de Samuel e os dois livros dos Reis.

8 Partes dos livros de Isaías, Jeremias, Ezequiel, assim como de outros livros proféticos menores.

9 Mesmo entre os chamados livros poéticos foi utilizada a prosa, como no início e final do livro de Jó (capítulos 1-2 e parte do 42). Há também a presença majoritária da prosa em Rute, Ester, Daniel, Esdras, Neemias e nos dois livros de Crônicas.
} 
E aqui encontrou-se certa dificuldade em virtude da formação acadêmica dos pesquisadores e alunos. Havia aqueles originários da área de Letras, com maior facilidade para compreender e exercitar a teoria e a crítica literária, mas com pouca ou nenhuma formação na área dos estudos bíblicos. E o oposto se deu também. Pesquisadores e estudantes com formação em exegese bíblica, mas sem maiores conhecimentos da teoria e da crítica literária.

Em virtude dessa configuração foi necessário um nivelamento de conhecimentos, o que reafirmou a importância dos estudos teóricos. Durante o primeiro semestre de 2018, em reuniões quinzenais, o grupo estudou tanto teóricos da literatura quanto o uso que deles faziam exegetas na aplicação aos textos religiosos. Tal metodologia mostrou-se produtiva, trazendo maior conhecimento e segurança no uso e na aplicação de teorias. Também foram introduzidos elementos teóricos do campo da exegese bíblica, necessários para a compreensão dos livros bíblicos em seus contextos de produção e recepção originários, o que permitiu a prática de uma crítica literária que compôs aspectos sincrônicos com diacrônicos.

Tal empenho produziu como resultado a análise literária de textos bíblicos a partir de palestras proferidas por membros do projeto durante 2018, como: O narrador e o evangelho de Marcos: discipulado, ocultamento, revelação e A ficcionalização de espaços narrativos no texto bíblico: o evangelho de Mateus, pelo dr. João Leonel; Sob a direção de uma voz: lendo Crônicas como literatura, pelo doutorando Ricardo Toniolo; e A Parábola do Semeador: uma análise literária do uso em Marcos e da releitura em Mateus, pelo doutorando Marcelo da Silva Figueiredo. Inclui-se, nesse tópico, o livro publicado pelo dr. Jonathan Luís Hack: Teologia e literatura: o texto bíblico como arte literária (2019).

Houve, ainda, o interesse por uma terceira categoria de análise, voltada não apenas para os textos bíblicos em si, mas especialmente para suas leituras, para sua recepção, para os usos que foram e ainda são feitos dos textos bíblicos, para as manifestações físicas dessas leituras etc. Esse tipo de trabalho se interessa pelo modo como determinada passagem foi lida, compreendida, aplicada; se interessa pela marginália ${ }^{10}$, pelas marcas que leitores particulares deixaram na história da leitura bíblica.

Estiveram entre nossos interesses, noutras palavras, os estudos da recepção dos textos bíblicos, o estudo das análises anteriormente produzidas, o conhecimento dos modos de uso, das diferentes edições da Bíblia, os modos como as ideologias se materializam nas obras impressas, como os leitores são influenciados e como reagem a essas ideologias.

Para tais estudos foram fundamentais os elementos teóricos advindos da História Cultural, principalmente aqueles propostos por Roger Chartier. Para o desenvolvimento de uma História da Leitura, ele propõe ser necessário:

[...] reconstruir as variações que diferenciam os "espaços legiveis" - isto é, os textos nas suas formas discursivas e materiais - e as que governam as circunstâncias de sua "efetuação" - ou seja, as leituras compreendidas como práticas concretas e como procedimentos de interpretação.

10 Maria do Céu Estibeira (2010, p. 130) define marginália dizendo: "O termo marginalia, do adjetivo latino marginalis, significando 'à margem de', refere-se, portanto, aos comentários ou às notas escritas nas margens ou noutros espaços em branco junto do texto de uma página impressa, nas folhas em branco ou nas folhas de guarda de um livro e foi importado de Coleridge, o qual veio a revelar-se um mestre exímio desta técnica e a tornar-se numa referência na história da anotação". 
[...] Três polos, em geral separados pela tradição acadêmica, definem o espaço dessa história: de um lado, a análise dos textos, sejam eles canônicos ou profanos, decifrados nas suas estruturas, nos seus objetivos, em suas pretensões; de outro lado, a história do livro, além de todos os objetos e de todas as formas que toma o escrito; finalmente, o estudo de práticas que se apossam de maneira diversa desses objetos ou de suas formas, produzindo usos e significações diferenciados (CHARTIER, 2017, p. 12).

As articulações propostas por Chartier regeram, de uma forma ou de outra, parte da produção acadêmica desenvolvida no projeto. E, de modo particular, os seguintes resultados: A Arca de Noé em bíblias de estudo brasileiras: recepção e formação de leitores, comunicação pelo dr. João Leonel; Salmos de peregrinação: uma história de sua leitura e Gênesis 38 nas bíblias de estudo, comunicações pelo dr. Jonathan Luís Hack.

Como derivação das pesquisas sobre Bíblia como literatura, e em virtude da presença do texto sagrado em considerável segmento da ficção nacional, deu-se também importância ao estudo da relação entre eles. Para isso, estudou-se como a temática e textos bíblicos se tornam material composicional na ficção pátria. Nesse contexto, foram produzidos: Éden e deserto revisitados: Aniquilação, de Jeff Vandermer, Os detetives selvagens, de Roberto Bolaño e Literatura brasileira e a Bíblia: ferramentas para o diálogo com o modernismo e o contemporâneo, comunicações proferidas pelo dr. Cristhiano Motta Aguiar; o livro organizado pelos doutores Alexandre Huady T. Guimarães e João Leonel, Literatura brasileira e religiosidade (2018), e o capítulo de livro, "Leituras e escritas em 'A mulher que escreveu a Bíblia', de Moacyr Scliar (2018), por João Leonel.

\section{Resultados}

A análise literária aplicada aos estudos das narrativas bíblicas já tem sido experimentada e aperfeiçoada em vários trabalhos de pesquisa realizados no Programa de Pós-Graduação em Letras da UPM. Ainda assim, supomos que o projeto desenvolvido em 2018 ampliou as possibilidades dentro e fora da universidade, fez crescer o alcance desse tipo de trabalho, divulgou pesquisas que têm sido efetuadas no Brasil e no exterior e produziu materiais que, certamente, continuarão servindo àqueles que porventura se interessem por nosso campo de estudos.

Seguem abaixo alistados os resultados obtidos pelo projeto de pesquisa, divididos em seis itens que revelam a amplitude e a diversidade de ações que foram efetivadas, salientando o apoio, tanto financeiro quanto logístico, fornecido pela equipe do MackPesquisa:

\section{Divulgação por meio de comunicações e palestras}

Palestra. LEONEL, João. Bíblia como literatura: perspectivas e desenvolvimentos no Brasil e no exterior. 2018. 3 ${ }^{a}$ Jornada Bíblia e Literatura. 16/10/2019. Realização. Núcleo Multidisciplinar de Estudos do Protestantismo (Numep, CNPq); Centro de Estudos de Literatura, Teorias do Fenômeno Religioso e Artes (Celta/Unicamp); Programa de Pós-Graduação em Letras (CCL/UPM); Graduação em Teologia (Ceft/UPM); Graduação em Letras (CCL/UPM). 
Palestra. LEONEL, João. O narrador e o evangelho de Marcos: discipulado, ocultamento, revelação. 2018. $3^{\circ}$ Congresso Nacional Letras em Rede. Mesa 14. Bíblia na Literatura. Universidade Presbiteriana Mackenzie.

Palestra. TONIOLO, Ricardo. Sob a direção de uma voz: lendo Crônicas como literatura. $3^{a}$ Jornada Bíblia e Literatura. 16/10/2019. Realização: Núcleo Multidisciplinar de Estudos do Protestantismo (Numep, CNPq); Centro de Estudos de Literatura, Teorias do Fenômeno Religioso e Artes (Celta/Unicamp); Programa de Pós-Graduação em Letras (CCL/UPM); Graduação em Teologia (Ceft/UPM); Graduação em Letras (CCL/UPM).

Comunicação. LEONEL, João. A Arca de Noé em bíblias de estudo brasileiras: recepção e formação de leitores. In: Congresso Internacional Arca de Noé: catástrofe e redenção, 2018, Aveiro, Portugal. Livro de resumos. Aveiro, Portugal: UA Editora. Universidade de Aveiro, 2018. v. 1. p. 34-34.

Comunicação. LEONEL, João. A ficcionalização de espaços narrativos no texto bíblico: o evangelho de Mateus. In: Congresso Internacional 2018. Circulação, Tramas \& Sentidos na Literatura, 2018, Uberlândia, MG. Caderno de Resumos do Congresso Internacional Abralic 2018. Uberlândia, MG: Abralic, 2018. v. 1. p. 439-439.

Comunicação. LEONEL, João. Recepção e Bíblia no Brasil: análise da narrativa do dilúvio em bíblias de estudo. 2018. $3^{\circ}$ Congresso Nacional Letras em Rede, Simpósio X: Bíblia como literatura. Universidade Presbiteriana Mackenzie.

Comunicação. AGUIAR, Cristhiano Motta. Éden e deserto revisitados: Aniquilação, de Jeff Vandermer, e Os detetives selvagens, de Roberto Bolaño. 2018. Comunicação apresentada no simpósio Literatura e Religiosidade, Abralic 2018.

Comunicação. AGUIAR, Cristhiano Motta. Literatura brasileira e a Bíblia: ferramentas para o diálogo com o modernismo e o contemporâneo. 2018. Comunicação apresentada na Mesa Temática "Bíblia na Literatura", no $3^{\circ}$ Congresso Nacional Letras em Rede, 2018, Mackenzie.

Comunicação. HACK, Jonathan Luís. Gênesis 38 nas bíblias de estudo. $3^{\circ}$ Congresso Nacional Letras em Rede, 2018. Simpósio X: Bíblia como literatura. Universidade Presbiteriana Mackenzie.

Comunicação. HACK, Jonathan Luís. Salmos de peregrinação: uma história de sua leitura. $3^{\circ}$ Congresso Nacional Letras em Rede, 2018. Simpósio X: Bíblia como literatura. Universidade Presbiteriana Mackenzie.

Comunicação. VIEIRA, Leni Soares. Um estudo sobre adaptações do texto bíblico de Josué 2.1-24: Raabe, a história de fé de uma prostituta. $3^{\circ}$ Congresso Nacional Letras em Rede, 2018. Simpósio X: Bíblia como literatura. Universidade Presbiteriana Mackenzie.

Comunicação. FREITAS, Priscilla Cláudia Pavan de. A construção da imagem de Jesus em "Cristo Deus Shiva": uma leitura semiótica e reflexiva. 2018. $3^{\circ}$ Congresso Nacional Letras em Rede, Simpósio X: Bíblia como literatura. Universidade Presbiteriana Mackenzie.

Comunicação. FIGUEIREDO, Marcelo da Silva. A Parábola do Semeador: uma análise literária do uso em Marcos e da releitura em Mateus. 2018. $3^{\circ}$ Congresso Nacional Letras em Rede, 2018. Simpósio X: Bíblia como literatura. Universidade Presbiteriana Mackenzie. 


\section{Realização de eventos}

\section{$2^{\text {a }}$ Jornada Bíblia e Literatura - 15 e 23/05/2018.}

Palestras:

- Dra. Suzana Chwarts (USP): “Autoridade e poder na família patriarcal de Isaac e Rebeca: uma leitura atenta de Gênesis 25 e 27".

- Dr. Marcos Aparecido Lopes (Unicamp): "O estatuto da imagem no âmbito da liturgia e das artes poéticas".

- Dr. Thiago Blumenthal: "As espirais bíblicas em Franz Kafka” (pós-doutorando Letras/Mackenzie).

\section{$3^{a}$ Jornada Bíblia e Literatura - 16 e 17/10/2018.}

\section{Palestras:}

- Sob a direção de uma voz: lendo Crônicas como literatura. Doutorando Ricardo Toniolo (Numep/CNPq; FITR).

- Bíblia como literatura: perspectivas e desenvolvimentos no Brasil e no exterior. Dr. João Leonel (Numep/CNPq; UPM/Pós-Graduação Letras).

- A ambivalência textual no conto "Via Crucis", de Clarice Lispector. Doutorando Thiago Cavalcante Jeronimo (UPM/Pós-Graduação Letras).

- Mística como crítica na poesia militante de Violeta Parra. Dra. Ceci Maria Costa Baptista Mariani (PUC Campinas. Pós-Graduação Ciências da Religião).

\section{Criação do site Bíblia e Literatura}

Criação do site Bíblia e Literatura (http:/ / bibliaeliteraturamackenzie.com/) $)^{11}$ para divulgação de eventos, veiculação de produção acadêmica, textos de divulgação e sugestões bibliográficas ligados às pesquisas sobre Bíblia e Literatura.

\section{Produção bibliográfica}

\section{Livros:}

LEONEL, J. (org.). Bíblia, literatura e recepção. Livro a ser publicado neste ano (2021) com capítulos que constituem resultado do projeto de pesquisa. Além dos pesquisadores ligados ao projeto, farão parte professores de universidades nacionais e internacionais.

LEONEL, J.; GUIMARÃES, A. H. T. (org.). Literatura brasileira e religiosidade. São Paulo: Editora Mackenzie, 2018.

LEONEL, J.; SANTOS, L. F. (org.). Teologia do diálogo. Pastorais. São Paulo: Fonte Editorial, 2018.

HACK, J. L. Teologia e literatura: o texto bíblico como arte literária. São Paulo: Fonte Editorial, 2019.

\section{Capítulos de livros:}

LEONEL, J. Leituras e escritas em "A mulher que escreveu a Bíblia", de Moacyr Scliar. In: GUIMARÃES, A. H. T.; LEONEL, J. (org.). Literatura e religiosidade. São Paulo: Editora Mackenzie, 2018. p. 277-308. 
LEONEL, J. Bíblia e literatura: relação e complementação. In: BRITO, Regina; TREVISAN, Ana Lúcia; DUARTE, Marcos. (org.). Estudos textuais e discursivos em múltiplas perspectivas. São Paulo: Editora Mackenzie, 2019, p. 135-157.

LEONEL, J. Cenários e a constituição do sentido no evangelho de Mateus.

A ser publicado em 2021 no livro LEONEL, J. (org.). Bíblia, literatura e recepção. com resultados do projeto de pesquisa.

LIMA, A. de O. Introdução ao livro de Amós. In: PROENÇA, A.; PROENÇA, E. de; ROSSI, L. A. S. (org.). Bíblia tradução brasileira: introduções acadêmicas. São Paulo: Fonte Editorial/SBB, 2018. p. 820-824.

AGUIAR, C. M. Imagens da Bíblia na poesia épica brasileira: Frei Manuel de Santa Rita Itaparica e Olavo Bilac. A ser publicado em 2021 no livro LEONEL, J. (org.). Bíblia, literatura e recepção.

AGUIAR, C. M. Narrativa bíblica e espaço: uma análise da representação do espaço em Gênesis 24. In: BRITO, Regina; TREVISAN, Ana Lúcia; DUARTE, Marcos. (org.). Estudos textuais e discursivos em múltiplas perspectivas. São Paulo: Editora Mackenzie, 2019, p. 51-67.

Artigo:

LIMA, A. de O. Ateologia bíblica: convite a uma exegese laica. Cadernos de Fé e Cultura, v. 3, p. 57-65, 2018.

\section{Convênios realizados}

Durante o ano de 2018, foram realizados convênios com dois grupos de pesquisa de universidades públicas:

- Centro de Estudos de Literatura, Teorias do Fenômeno Religioso e Artes (Celta) - Universidade Estadual de Campinas (Unicamp), por meio do prof. dr. Marcos Aparecido Lopes, coordenador do referido centro. O Celta participou da organização da $3^{\text {a }}$ Jornada Bíblia e Literatura por meio do prof. dr. Marcos Aparecido Lopes.

- Grupo de Pesquisas Filosofia e Literatura: o Sagrado e a História - Universidade Federal de Campina Grande (UFCG), por meio de seu coordenador, prof. dr. João Marcos Leitão Santos.

\section{Aquisição de bibliografia especializada}

Por meio de verba aprovada pelo Fundo MackPesquisa foram adquiridos livros, tanto nacionais quanto internacionais, que versam sobre o tema do projeto em tal volume que o Mackenzie passa a ser a universidade com um dos maiores acervos sobre Bíblia e Literatura no Brasil.

\section{Conclusão}

O financiamento do projeto viabilizou criação de site, viagens de pesquisadores, compra de equipamento e de livros, criando, dessa forma, condições propícias para que resultados fossem obtidos.

Isso pode ser constatado por meio de contatos obtidos pelo pesquisador lider João Leonel, que em viagem à Espanha e Portugal manteve contato com as profas. 
dras. Paula Almeida Mendes, da Universidade do Porto, Portugal e Carmen Yebra Rovira, da Universidad Pontificia de Salamanca, Espanha, que aceitaram contribuir com capítulos para o livro que será publicado em 2021, com o título de Bíblia, literatura e recepção, organizado pelo pesquisador líder e contendo capítulos que representam resultados da pesquisa, assim como textos de professores pesquisadores de outras universidades brasileiras.

Do mesmo modo, a participação do pesquisador Jonathan Luís Hack no Society of Biblical Literature Annual Meeting, entre 17 a 21 de novembro de 2018, em Denver, Estados Unidos, possibilitou o convite e sua aceitação pela profa. dra. Angela Parchen Rasmussen (Universidade Georgetown, Estados Unidos), para que participasse do referido livro.

Os resultados alistados anteriormente indicam o alto grau de produção do grupo de pesquisa, o que, por si só, aponta para o sucesso do projeto. Tal situação motiva o grupo a manter seus esforços de pesquisa no campo, ampliando-o e aprofundando-o, com vistas a tornar a UPM referência nacional nos estudos da Bíblia como literatura.

\section{LiteraRY READING OF THE BIBLE: A PROJECT}

Abstract: This paper presents the research project "Literary analysis of narratives: new methodologies for teaching biblical interpretation", as well as its results. This project was developed during 2018 with funding from the Fundo MackPesquisa, applying principles of literary theory to the interpretation of narrative texts of the Bible. In 2021 a book will be published with chapters written by members of the group and guests from national and international colleges.

Keywords: Literature. Narrative. Bible. Interpretation. Reading.

\section{REFERÊNCIAS}

AGUIAR, C. M. Narrativa bíblica e espaço: uma análise da representação do espaço em Gênesis 24. In: BRITO, Regina; TREVISAN, Ana Lúcia; DUARTE, Marcos. (org.). Estudos textuais e discursivos em múltiplas perspectivas. São Paulo: Editora Mackenzie, 2019, p. 51-67.

ALTER, R. A arte da narrativa bíblica. São Paulo: Companhia das Letras, 2007.

ALTER, R. The art of biblical narrative. New York: Basic Books, 1981.

ALTER, R.; KERMODE, F. (org.). Guia literário da Bíblia. São Paulo: Unesp, 1997.

ALTER, R.; KERMODE, F. (ed.). The literary guide to the Bible. Cambridge, Mass: Harvard University Press, 1987.

BAR-EFRAT, S. Narrative art in the Bible. Sheffield: Sheffield Academic Press, 1989.

BERLIN, A. Poetics and interpretation of biblical narrative. Sheffield: Almond Press, 1983.

BÍBLIA. Novo Testamento: os quatro Evangelhos. Tradução do grego por Frederico Lourenço. São Paulo: Companhia das Letras, 2017. v. 1. 
BÍBLIA. Novo Testamento: Apóstolos, Epístolas, Apocalipse. Tradução do grego por Frederico Lourenço. São Paulo: Companhia das Letras, 2018. v. 2.

BÍBLIA. Antigo Testamento: Os Livros Proféticos. Tradução do grego por Frederico Lourenço. São Paulo: Companhia das Letras, 2019. v. 3.

BLOOM, H. The shadow of a great rock: a literary appreciation of the King James Bible. Yale: Yale University Press, 2012.

CHARTIER, R. A ordem dos livros: leitores, autores e bibliotecas na Europa entre os séculos XIV e XVIII. 2. ed. Brasília: Editora UnB, 2017.

ESTIBEIRA, M. do C. Uma perspectiva da marginália de Fernando Pessoa. Patrimônio e Memória, v. 6, n. 1, p. 129-145, 2010.

FERNANDES, L. S. V. Imagens da mulher no evangelho de Mateus: a construção de personagens femininas. 2014. 158 f. Dissertação (Mestrado em Letras) - Universidade Presbiteriana Mackenzie, São Paulo, 2014.

FERNANDES, L. S. V. "Os céus e a terra passarão, mas as minhas palavras não hão de passar": os efeitos dos cronotopos no evangelho de Mateus. 2019. 163 f. Tese (Doutorado em Letras) - Universidade Presbiteriana Mackenzie, São Paulo, 2019.

FOKKELMAN, J. P. Vertelkunst in de bijbel een handleiding bij literair lezen. Uitgeverij Boekencentrum: Zoetermeer, 1995.

FOKKELMAN, J. P. Reading biblical narrative: an introductory guide. St. Louis: Westminster John Knox, 1999.

FRYE, N. O código dos códigos: a Bíblia e a literatura. São Paulo: Boitempo, 2004. FRYE, N. The great code: the Bible and literature. New York: Academic Press, 1982.

GABEL, J. B.; WHEELER, C. B. The Bible as literature: an introduction. New York: Oxford University Press, 1986.

GUIMARÃES, A. H. T.; LEONEL, J. (org.). Literatura brasileira e religiosidade. São Paulo: Editora Mackenzie, 2018.

HACK, J. L. Gênesis 38: análise literária e história da leitura. 2017. 280 f. Tese (Doutorado em Letras) - Universidade Presbiteriana Mackenzie, São Paulo, 2017.

HACK, J. L. Teologia e literatura: o texto bíblico como arte literária. São Paulo: Fonte Editorial, 2019.

LEONEL, João. Bíblia e Literatura: relação e complementação. In: BRITO, Regina; TREVISAN, Ana Lúcia; DUARTE, Marcos. (org.). Estudos textuais e discursivos em múltiplas perspectivas. São Paulo: Editora Mackenzie, 2019, p. 135-157.

LIMA, A. de O. A Bíblia como literatura - a Bíblia como ficção. Estudos de Religião, v. 29, n. 1, p. 153-168, jan./jun. 2015.

LIMA, A. de O. A Bíblia como literatura no Brasil: história e análise de novas práticas de leitura bíblica. 2015. 209 f. Tese (Doutorado em Letras) - Universidade Presbiteriana Mackenzie, São Paulo, 2015.

LIMA, A. de O. A teologia bíblica: convite a uma exegese laica. Cadernos de Fé e Cultura, v. 3, p. 57-65, 2018.

LONGMAN III, T. Literary approaches to biblical interpretation. Grand Rapids: Zondervan, 1987. 
MAGALHÃES, A. Deus no espelho das palauras. 2. ed. rev. e ampliada. São Paulo: Paulinas, 2009.

MARGUERAT, D.; BOURQUIN, Y. Para ler as narrativas bíblicas: iniciação à análise narrativa. São Paulo: Loyola, 2009.

MARGUERAT, D.; BOURQUIN, Y. Pour lire les récits bibliques. La Bible se raconte. Initiation à l'analyse narrative. Paris: Les Éditions du Cerf, 1998.

PETERSEN, N. R. Literary criticism for New Testament critics. Philadelphia: Fortress, 1978.

POWELL, M. A. What is narrative criticism? Minneapolis: Augsburg Fortress, 1990.

RETRATOS DA LEITURA NO BRASIL. Disponivel em: http://prolivro.org.br/ home/index.php/atuacao/25-projetos/pesquisas/3900-pesquisa-retratos-daleitura-no-brasil-48. Acesso em: 10 abr. 2019.

RYKEN, L. How to read the Bible as literature... and get more out of it. Grand Rapids: Zondervan, 1984.

RYKEN, L. Para ler a Bíblia como literatura: e aprender ainda mais com ela. São Paulo: Cultura Cristã, 2018.

RYKEN, L. Words of delight: a literary introduction to the Bible. 2. ed. Grand Rapids: Baker, 1992.

SILVA, C. M. D. da. Leia a Bíblia como literatura. São Paulo: Loyola, 2007. (Ferramentas Bíblicas, 1).

SILVANO, Z. Introdução à análise poética de textos bíblicos. São Paulo: Paulinas, 2014. (Série Bíblia como literatura, v. 5).

STERNBERG, M. The poetics of biblical narrative: ideological literature and the drama of reading. Bloomington: Indiana University, 1987.

TONIOLO, R. C. O narrador no livro das crônicas: estratégias narrativas para o estabelecimento de um novo discurso religioso. 2017. 146 f. Dissertação (Mestrado em Letras) - Universidade Presbiteriana Mackenzie, São Paulo, 2017.

VITO, Francikley. Logos em luta: diálogo como artificio literário no Quarto Evangelho. 2014. 150 f. Dissertação (Mestrado em Letras) - Universidade Presbiteriana Mackenzie, São Paulo, 2014.

VITÓRIO, J. Análise narrativa da Bíblia: primeiros passos de um método. São Paulo: Paulinas, 2016. (Série Bíblia como literatura, n. 8).

ZABATIERO, J. P. T. Manual de exegese. São Paulo: Hagnos, 2007.

ZABATIERO, J. P. T.; LEONEL, J. Bíblia, literatura e linguagem. São Paulo: Paulus, 2011. 


\section{APÊNDICE}

\section{Participantes do projeto}

1. Professores pesquisadores:

- Dr. João Leonel - Professor Pesquisador Líder - Pós-Graduação e Graduação em Letras, UPM.

- Dr. Cristhiano Motta Aguiar - Professor Pesquisador - Pós-Graduação e Graduação em Letras, UPM.

- Dr. Jonathan Luís Hack - Professor Pesquisador - Graduação em Teologia, UPM.

\section{Pesquisadores voluntários:}

- Dr. Anderson de Oliveira Lima - Professor Pesquisador.

- Doutoranda Larissa de Macedo Raymundo - Universidade de Salamanca, Espanha.

- Mestre Francikley Vito.

- Mestre Ricardo César Toniolo.

3. Alunos de pós-graduação:

- Doutoranda Leni Soares Vieira - Pós-Graduação em Letras, UPM.

- Doutoranda Priscilla Cláudia Pavan de Freitas - Pós-Graduação em Letras, UPM.

- Doutorando Marcelo da Silva Figueiredo - Pós-Graduação em Letras, UPM.

- Mestrando Carlos Roberto Miranda - Pós-Graduação em Letras, UPM.

4. Alunos de graduação:

- Letícia Prado Leporini - Graduação em Letras, UPM.

- Mário Coutinho dos Santos - Graduação em Letras, UPM.

- Matheus de Siqueira Nunes - Graduação em Letras, UPM. 